\title{
Romance de estrada: memória afetiva e sexualidade em Carol Bensimon
}

\author{
Helena González Fernández ${ }^{1}$
}

Todos nós adorávamos caubóis (2013) ${ }^{2}$ é o terceiro livro da escritora gaúcha Carol Bensimon, mas também sua contribuição para uma atualização da road fiction, na qual procura um lugar de enunciação em que o queer satura qualquer definição da subjetividade, das identidades (cultural, nacional, decolonial) e de qualquer diferença que atravesse os corpos das protagonistas e pretenda encaixá-los em definições restritas. Superando preconceitos, é o deslocamento o que permite mostrar em primeiro plano a negociação dos afetos e da interseccionalidade. $\mathrm{O}$ corpo e o território, em primeiro plano. ${ }^{3}$

O romance apresenta um percurso crítico pela geografia física e humana do Rio Grande do Sul, mas o âmago dessa história é o retrato geracional de mulheres do começo do século XXI enquanto sujeitos não limitados pela "heterossexualidade obrigatória" (Rich, 1980) nem pelos seus dispositivos disciplinares (moral, matrimônio, família nuclear, modelos de gênero/sexualidade etc.). Duas garotas de distinta procedência social e geográfica, que se conhecem desde a adolescência, reencontram-se anos mais tarde para fazerem juntas uma viagem longamente adiada pelo território, em grande medida desconhecido, do Rio Grande do Sul. Cora é uma lésbica consciente das suas preferências sexuais, que aprecia a estética contracultural e estuda moda em Paris. Julia, por sua vez, apresenta-se mais indefinida e indecisa, característica que se destaca pelo fato de descender de uma família de emigrantes italianos, católicos e conservadores, habitantes do interior, em Soledade. Durante um tempo, atuou como jornalista em Montreal, onde tem um namorado turco-americano. $\mathrm{O}$ marco de definição genérico-sexual do romance responde às dissidências sexuais da contemporaneidade, e

\footnotetext{
${ }^{1}$ Doutora em literatura galega e professora da Universitat de Barcelona, Barcelona, Espanha. Email: helenagonzalez@ub.edu

2 Também traduzido para o espanhol pela Continta me Tienes, editora especializada em ficção sobre as identidades sexuais (Bensimon, 2015).

${ }^{3}$ Este artigo é resultado do projeto de pesquisa "Teoría de las Emociones y el Género en la Cultura Popular del Siglo XXI" (FEM2014-57076-P) e do GRC Grup de Recerca Consolidat Creació i Pensament de les Dones (2014 SGR 44).
} 
Bensimon não procura os personagens contrários para articular uma ficção modelizadora, moralista ou melodramática, mas para habilitar um espaço fluido, um espaço não bem definido.

Todos nós adorávamos caubóis é um romance de traço rápido. Boa parte de sua receita funda-se no distanciamento por meio do humor e a interdiscursividade, da paródia dos relatos turísticos e do flash-back recorrente até o final. Sua narrativa procura a desestabilização e escapa a qualquer univocidade, mantendo-se longe da via patética e contra uma previsível perspectiva moralista, embora seja um texto politicamente afirmativo. Procura-se, assim, que a ficção queerize não apenas a identidade sexual mas também as referências culturais e a estrutura mesma do relato.

\section{Espaços e corpos}

Os espaços - fundamentais nos livros anteriores de Carol Bensimon, Pó de parede (2008) e Sinuca embaixo d'água (2009) - devem ser entendidos como passagem, como viagem por uma paisagem afetiva não experiencial, mas aprendida na medida em que faz parte do legado dos discursos e práticas que querem definir naturalmente os corpos pelo território de origem. O surpreendente protagonismo dos caubóis no título leva a pensar nas formas específicas de morar num lugar fortemente condicionado pela dureza extrema e pelo movimento, o que permite relacionar o Rio Grande do Sul tradicional a um gênero cinematográfico popular, o western. A autora pensou outros títulos para o livro, mas, finalmente, a figuração do caubói ficou como chave interpretativa desse romance que, contudo, é protagonizado por duas garotas que nada têm a ver com a ambientação tradicional gaúcha, mas que gostam de ver filmes do faroeste.

Minha primeira tentativa foi Caubóis, mas ele não teve uma vida longa e logo deu lugar a Faíscas. Fiquei com essa opção por bastante tempo, e inclusive o primeiro capítulo do romance foi publicado com esse título na revista inglesa Granta. Mas, quando o romance chegou na Companhia das Letras, o pessoal implicou um pouco com Faíscas, e acabaram me sugerindo Todos nós adorávamos caubóis, que é uma frase que está no livro (Morães, 2013, s.p.).

É interessante a insistência nos caubóis na medida em que adiciona uma nova modulação queer, voltando-se para o feminino do cronotopo 
decolonial americano, significativamente situado nos espaços extensos e sem fronteira; espaços que ultrapassam a medida humana, onde as regras ficam submetidas à experiência da paisagem e à sobrevivência nela, onde a única forma de pertencimento é o deslocamento dos corpos numa forma de nomadismo ganadeiro que rompe com a ideia de pertencimento a um lugar bem delimitado. A representação dessa vivência específica das paisagens abertas conforma um proveitoso imaginário épico situado nos grandes territórios do continente americano (pampa, sertão, faroeste) habitados por heróis quotidianos (gaúcho, caubói) e nem sempre a cavalo (o retirante sertanejo). ${ }^{4}$ A cultura contemporânea tem dado relatos queer que põem em questão esses espaços hipercaracterizados como masculinos. Em Thelma $\mathcal{E}$ Louise, road movie de Ridley Scott (1991), duas mulheres heterossexuais trocam a casa pela estrada e pelos hotéis, já em Transamérica (2005), filme independente dirigido por Duncan Tucker, uma transgênero feminina que está na fase de conclusão do processo de redesignação descobre uma paternidade imprevista, e a história se desenrola enquanto guia o carro pela estrada. Em Brokeback Mountain (2005), dirigida por Ang Lee, há um retorno ao cavalo; dois caubóis ficam apaixonados um pelo outro. Mas há ainda um interessante antecedente no imaginário brasileiro, o inevitável sertão queerizado de Grande Sertão: veredas.

Mas, como a figura masculina, patriarcal, heterossexual e conservadora do caubói (e do gaúcho) pode servir para titular um romance sobre os afetos lésbicos sem que as protagonistas sejam masculinizadas? Nos corpos de Cora e Julia confluem diversas tensões: a família; as diferenças sociais e econômicas, bem como as expectativas que esse fato gera; e um complexo debate geopolítico no qual as identidades abrem inúmeros conflitos. Num primeiro nível, nacional, aparecem as tensões do discurso identitário cultural/regional gaúcho a respeito do brasileiro e a definição da comunidade de pertença. Num segundo nível, o decolonial, a complexa identidade brasileira entra em contato com a ocidental e, em particular, com a europeia, que atua seguindo uma lógica não declarada e dissimulada sob a retórica da modernidade, como argumentou Walter Mignolo (Lastra, 2008, p. 290). Julia representa a garota típica que incorpora os valores das cidades do interior, a

\footnotetext{
${ }^{4}$ A galeria de figurações completa-se com os vingadores desses territórios, particularmente o cangaceiro e o pistoleiro.
} 
memória da pobreza, as migrações (da Europa pobre para a América selvagem, e da cidade do interior para a cidade da costa), a moral conservadora, os modelos de sucesso social baseados no trabalho, a preferência pela moda mais convencional (quer dizer, pela integração no marco normativo). Cora, sua antítese, é a representante da contracultura, de família não nuclear, formada numa cidade moderna, com boa posição social e econômica, o que lhe permite ir estudar moda em Paris. Devido a esse deslocamento transatlântico, participa no tópico da intelectual/artista brasileira que descobre na França sua diferença cultural como emigrante estrangeira e, por isso, deve dar resposta com a sua atividade artística à distância cultural, seguindo a receita modernista: fazer uma proposta inovadora a partir de elementos próprios da originalidade nativa. Sobre moda e identidade, falar-se-á mais adiante.

\section{A viagem}

A viagem abre a oportunidade do reencontro no território afetivo e sexual e, ao mesmo tempo, serve para negar qualquer preconceito identitário entendido como pertencimento e determinante, e é por isso que se observam com distância e desconfiança os territórios e os espaços de origem tanto a familiar quanto a gaúcha. A viagem adiada ativa ao mesmo tempo os mecanismos da memória afetiva e da experiência. Isso permite abordar a problemática que geram os legados normativos herdados e lançar perguntas com respeito à identidade, à sexualidade, à família, ao corpo, ao imaginário cultural de sua geração e à idiossincrasia gaúcha, dentro do que Jacques Derrida denomina o "arquivo" e Marta Segarra o "patriarquivo" (Derrida, 1995; Segarra, 2014, p. 178; González Fernández, 2015).

Todos nós adorávamos caubóis parte do sujeito excêntrico feminino e lésbico desdobrado em duas personagens diferenciadas e em trânsito, Cora e Julia. Embora as duas protagonistas sejam representações de uma sexualidade queer, o romance não busca personagens modalizadoras, muito pelo contrário, o objetivo é queerizar, estranhar, desestabilizar, problematizar a experiência identitária, afetiva e sexual. Em uma entrevista, Carol Bensimon descreve Cora assim:

Acho que a personagem vê o exercício de seu lado gay como uma certa transgressão. Ao mesmo tempo há uma limitação, prisão, sei 
lá como diz, um universo claustrofóbico. Ela fala num determinado momento que talvez se sinta mais atraída por meninas supostamente heterossexuais do que por lésbicas, e isso cria um certo problema. Ela fala nisso. Ela queria ter uma chance com qualquer pessoa que encontrasse na rua. [...] O livro fala mais das questões mal resolvidas entre Cora e Julia. Em nenhum momento a Cora chega a confrontar a Julia. [...]. Mantém-se uma ambiguidade que tem o seu lado aventureiro e seu lado angustiante (Bensimon, 2014, s.p.)

Essa fuga das personagens modalizadoras permite mostrar afinidades imprevistas, sublinhar as divergências, evidenciar as transformações que se produzem nas duas mulheres e fugir dos estereótipos reducionistas. O paralelo entre a geografia gaúcha retratada pela protagonista e o corpo das duas mulheres é evidente desde o princípio: encontram-se na tensão dos tópicos identitários, no processo mesmo de negociação do estereótipo e suas dissidências. Nem elas são apenas as mulheres "femininas" normativas do marco heterossexual nem o gaúcho entra no tópico identitário brasileiro. Carol Bensimon explica bem a queerização dos corpos e do território:

Nos meus dois livros, há muito pouco de Brasil, no sentido "cor local". Na verdade, essa questão identitária, o sentir-se brasileira ou não, só apareceu para mim quando eu fui morar em Paris, em 2008. Até porque no Rio Grande do Sul a gente se protege um pouco disso, se escondendo atrás da suposta identidade gaúcha, e essa identidade se apoia justamente no inverso do que é ser brasileiro (e, portanto, é uma construção parcialmente mentirosa) (Bensimon, 2012, s.p.)

Mas quanto as garotas conhecem realmente do território e da cultura do interior do Rio Grande do Sul? É possível o reconhecimento com a terra natal sem saudade? Todos nós adorávamos caubóis leva Cora e Julia a se encontrarem com a cultura herdada. Parte desse legado vem dado pela memória afetiva que as conecta a um lugar e uma forma de vida. Cora, como corresponde a uma família bem situada de Porto Alegre, reconhece, no primeiro trecho da viagem, as férias e a infância, um mundo já irrecuperável quer seja pelo divórcio ou porque seu pai está para ter outro filho com uma garota jovem. Julia, por seu turno, praticamente só conhece Soledade e, também no seu caso, a perda marca o encontro com as origens, um percurso que começa no cemitério, diante da tumba de seu 
irmão que morreu, Juliano. Em memória dele é que se chama Julia, uma referência espectral que leva a pensar até que ponto essa morte, da qual ela não participa, condiciona a sua vida como luto, o que a converte num corpo residual, numa vida que resta.

Não se procura delimitar os territórios geográficos e identitários com as ferramentas da exploração, por isso é que conduzem um carro antigo, sem GPS. A viagem foi planificada como achamento, um recurso, aliás, habitual na road fiction, porque o desejo de liberdade é incompatível com o roteiro marcado no mapa. E não pode haver saudade de uma paisagem desconhecida e desmemoriada, mais interessada no tipismo que em conservar os vestígios de sua própria história. A viagem, que tem início na BR-116, aparenta ser um encontro das duas garotas, das garotas com os territórios do interior, mas acaba por se resolver como um estranhamento, com final aberto no qual o questionamento da memória opera em dois níveis simultâneos: a memória afetiva enquanto casal e a memória histórica gaúcha.

O Rio Grande do Sul de Bensimon flutua entre o ódio a si próprio e um orgulho afirmativo reconhecível, insatisfeito, estranhado. Há vários indicadores no romance desse ódio que tem a ver com a incômoda paisagem rural do interior e a idealização do lugar onde morar "felizmente". O desejo das pessoas do interior não é ficar na bucólica pampa, como acontece com os pais de Julia, mas esquecer o território que foi ocupado como um faroeste, sair de qualquer coisa que seja esse interior gaúcho para aproximar-se do ideal confortável das cidades da costa. Procuram o esquecimento da miséria e dos padecimentos da emigração, a modernidade como explicitação do progresso, que permite superar uma memória de colonização, de trabalho e superação nos territórios incultos e não civilizados. Bensimon, que fez uma viagem para documentar o romance, chocouse com essa migração interior, mais uma mostra das dificuldades de "permanecer", de se "estabelecer" num lugar.

Uma coisa que descobri, quando me dispus a fazer essas viagens é que, na verdade, as pessoas destas cidades do interior não estão muito interessadas em "serem do interior". Seu ideal é o de se afastar da aura de bucolismo. Para elas, quanto mais urbanas elas parecerem, melhor. Por exemplo, as casas históricas de Antônio Prado (Bensimon, 2014, s.p.) 
A negação da própria história, a carência de uma memória comum que valorize mais os atos de heroicidade bélica ou simplesmente de superação das dificuldades que tiveram de superar os colonos marca a desafeição por uma identidade gaúcha que é considerada desmemoriada e frívola de mais. De fato, o aspecto mais relevante é a evidência da ideia de uma comunidade que tem um conflito aberto com o arquivo. Tradição e modernidade entram em conflito nas famílias migrantes do interior, porque são conservadores em suas práticas familiares no âmbito privado, mas mostram uma ânsia de modernidade em suas casas para mostrar de maneira pública o progresso econômico e, portanto, a superação da miséria. O patrimônio arquitetônico se perde. Bensimon, sensível e atenta esse valor arquitetônico, fica bastante incomodada e há diversos episódios no romance que retratam bem esse desalento. Para a autora, é contraditória essa ideia de tradição que converte as cidades do interior do Rio Grande do Sul em espaço fronteiriço, onde os valores são diferentes, embora a comparação com outras culturas marcadas pela migração torne isso compreensível: os costumes e saberes familiares afirmam uma identidade cultural diferenciada, mas as casas modernas, feitas com materiais da moda - mesmo demonstrando uma preferência pelo feio -, exibem progresso econômico.

Talvez o que mais tenha me marcado seja a relação contraditória que as pessoas estabelecem com as tradições. Nas cidades colonizadas por italianos, por exemplo, é visível o orgulho que as pessoas sentem de seus antepassados, e como se consideram mantenedoras de uma tradição, comer polenta, ter um fogão à lenha, falar o dialeto. Mas, na primeira oportunidade, elas destroem suas casas e erguem umas coisas monstruosas, provavelmente acreditando que o progresso tem aquela cara. Acho que toda cidade do interior vive nesse limiar confuso, entre o querer e o não querer ficar para trás (Bensimon, 2012, s.p.)

É a desmemória o que converte esses lugares habitados em faroeste, em terra de fronteira de limites esvaídos. Em lugares como Antônio Prado, a perda do patrimônio, a necessidade de desmemória é evidente: as velhas casas são o último vestígio da pobreza e do trauma da migração. E isso se reflete no romance: "tão logo a situação econômica permitia, as famílias de Antônio Prado, supostamente orgulhosas das suas origens, colocavam tudo abaixo e corriam para a loja mais próxima 
de materiais de construção, selecionando os piores tipos de revestimentos sob a crença de que eles eram muito mais modernos e práticos" (Bensimon, 2013, p. 34).

Um dos episódios mais interessantes e significativos se passa diante do monumento que a pátria gaúcha dedica aos irmãos Bertussi, no qual Cora faz a sua crítica à trivialização da memória histórica da comunidade.

Não é exagero afirmar que o tal memorial acabou sendo sem dúvida alguma o elemento mais estranho e fora de lugar que eu vi em toda a nossa viagem. Um desavisado podia mesmo ter a certeza de que aquele era um túmulo ao soldado desconhecido [...] mas daí bastaria que chegasse mais perto dessas mesmas estátuas para que a sua hipótese bélica se desfizesse em fiapos. Dois homens com duas gaitas? [...] Nada de cemitérios com cruzes brancas. Nada de filmes populares. Nada de lágrimas por estranhos. [...] Aquele monumento, com tudo, não homenageava nenhum soldado e nenhuma revolução, embora a linguagem tivera algo de grandiosa, e portanto ridícula (Bensimon, 2013, p. 41-42).

A reflexão sobre qual é o relato épico disponível da pátria gaúcha, quais os episódios de desmemória na luta pelas causas justas - a Guerra Farroupilha, por exemplo - ou os perigos da folclorização sentimental da diferença, impossibilitam às duas garotas, e em particular a Cora, o reencontro. Não há regresso possível. As cidades, as vilas, as paisagens gaúchas que elas vão descobrindo ativam os mecanismos do estranhamento, da mesma forma que as referências à família.

Porém, se no começo da viagem Cora destacava a falta de épica e o excesso de folclore como uma carência na identidade nacional, isso muda após seu regresso a Paris, onde, apesar da distância, percebe que é a modernização das teias e adornos gaúchos o que lhe permite criar um novo modelo de camisa, com ares de vanguarda, diferente e inovador. É o único momento em que Cora é capaz de manifestar seu orgulho, um orgulho criativo que parte da roupa tradicional gaúcha (2013, p. 177-178).

Quando Cora chegou a Paris, teve de enfrentar os estereótipos associados à "brasileira" - o que Walter Mignolo (2007, p. 17) chamou de pegada decolonial, uma sensação de inferiorização pelo fato de ela não responder aos relatos neocoloniais europeus, ou seja, não se apresentar como a mulata supostamente heterossexual chegada do Brasil. A inferiorização é reforçada, ainda, pela sua incômoda origem gaúcha, quer dizer, por não responder plenamente ao relato identitário nacional. 
O conflito identitário em Cora mostra-se desde a interseccionalidade e fica nesse interlúdio afirmativo, embora indefinido, do queer.

A queerização evita qualquer modalização unívoca do vínculo amoroso-sexual entre Cora e Julia. Aparece uma constelação afetiva que permite aprofundar em um caminho sem fim de estrangeirices. De fato, o namorado de Julia em Montreal, Eric Aslan, é um norte-americano de ascendência turca que, em virtude de sua aparência física, depois do 11 de setembro, passou a ser confundido com um perigoso terrorista árabe e é por isso que se desloca para o Canadá (Bensimon, 2013, p. 30). Esse episódio da contemporaneidade assemelha-se ao western, no que se refere à procura por foragidos. A fuga para Montreal provoca um efeito especular interessante, porque se Paris é a capital da moda e da modernidade na Europa, Montreal é sua antiga colônia, um território semelhante ao Rio Grande do Sul, que se define a si próprio como o estado mais "europeu" do Brasil e também conserva uma memória de independência. Esses lugares, opostos ao lugar-comum do que seja o Brasil ou o Canadá, ficam queerizados, vulneráveis em suas fronteiras quando Julia namora um personagem que resume as contradições da multiculturalidade depois do 11 de setembro. Os casais formados por Julia e Aslan e a mesma Julia e Cora representam a complexidade da negociação dos jovens sujeitos contemporâneos, atravessados pelas políticas multiculturais e decoloniais. Seus corpos são o resultado da "nova miscigenação" dessa mudança de século, na qual não apenas atua a raça, mas as intersecções culturais provocadas pelos movimentos migratórios e desterritorializações contínuas, aos quais se refere Walter Mignolo quando pensa a América Latina no século XXI.

Esses jovens são confrontados com problemas raciais, entremeados com questões de género e sexualidade, com problemas legais de imigração na Europa e nos Estados Unidos, e com um discurso que os desqualifica, direta ou indiretamente, como seres humanos e lhes fecha as portas (Lastra, 2008, p. 291, tradução nossa).

Na parte final do livro, quando, em Paris, Cora reflete sobre a impossibilidade de voltar ao Brasil, convertido em pátria de origem e de retorno impossível, afirma:

Julia ia chegar no dia seguinte. Era a sua primeira vez em Paris e o nosso primeiro encontro em cinco meses [...] havia me falado em voltar para o Brasil, mas o discurso parecia o daqueles 
expatriados que idealizam demais a terra natal, e que para seguirem idealizando precisam renunciar definitivamente a ela. A ideia de que o Brasil era o país do futuro só convencia quem estava fora dele (Bensimon, 2013, p. 179).

A viagem, pois, não está marcada pela epifania da identidade naturalizada em um território nem pela saudade, mas pela paródia crítica e a distância, as ferramentas que permitem que o romance incomode, interpele e leve o herdado a fórmulas arraigadas, mas inovadoras, como a camisa desenhada por Cora.

\section{Botas de homem: moda e identidade}

A moda atua como superfície de um retrato interior que nunca se oferece? Cora, a protagonista em primeira pessoa, estuda moda em Paris - figura típica de classe, a brasileira que se forma no estrangeiro. Porém, esse é um dado fundamental para interrogar a identidade a partir da interseccionalidade, inserir o questionamento acerca dos estereótipos de gênero, da sexualidade e da origem e, particularmente, sobre a importância que tem o vestuário como superfície de negociação identitária. $\mathrm{O}$ vestuário não é apenas um intensificador do personagem, mas o retrato mesmo, o que permite conhecer sua personalidade.

No começo da viagem, um homem usando o traje típico gaúcho repara no calçado de Cora:

"Essas tuas botas são de homem", ele disse, apontando para
dentro do carro [...]. Um tanto chocada, olhei para meus próprios
pés a fim de conferir o que era mesmo que eu usava, e eram meus
coturnos Doc Martens, pelos quais havia pagado uma pequena
fortuna em uma loja de marca em Paris. Aquele par de sapatos
tinha um pequeno altar reservado em quase todos os movimentos
de contracultura [...]. Este é o problema da moda: você depende
dos outros. Se eles não entenderem a mensagem, todos os seus
esforços vão por água abaixo (Bensimon, 2013, p. 13-14).

As botas Doc Martens de Cora revelam o mesmo conflito que a barba de Eric Aslan: dependem dos demais e por isso evidenciam o incômodo com a simplificação identitária, mas também retratam. Já na descrição do baile em que Cora e Julia se conhecem, Julia vai disfarçada de Penélope Charmosa, sublinhando a estilização da feminilidade normativa, enquanto Cora aparece vestida de punk, inclusive com uma seringa, 
destacando a contracultura e a ruptura com a norma. As botas mostram sua tentativa de fugir das convenções e da heteronormatividade, na medida em que consegue que seu corpo calce e mova-se com umas botas rijas e aparentemente masculinas, indicando metaforicamente que quem as calça poder ir a qualquer lugar. A moda é uma superfície de negociação da sexualidade e reafirma a personalidade e a consciência sobre a identidade sexual. Cora, com suas botas, reforça sua vontade de afirmar, visibilizar, explicitar, fazer-se entender em contraposição a qualquer norma.

A moda é, finalmente, o que permite resolver o conflito. Partindo da ideia de que o local é global, Cora resolve seu trabalho de faculdade com um desenho feito com materiais e formas gaúchas, para homens interessados no mais inovador e com capacidade para criar tendência.

De qualquer maneira, agora, integrados à camisa, os lenços haviam definitivamente ultrapassado as fronteiras do pampa. Um membro de um grupo indie meio performático ia arrasar com aquela roupa. Um artista que suspendesse partes de bicicletas no teto de museus pelo mundo afora ia arrasar com aquela roupa. Um escritor cujo livro inteiro fosse uma única frase de quinhentas páginas sem vírgulas ia causar muita inveja em seus pares se vestisse aquela roupa. Eu sentia um tremendo orgulho de mim mesma. E ainda havia ideias muito mais ambiciosas nos croquis (Bensimon, 2013, p. 177-178).

O orgulho afirmativo da estrangeira ao levar as formas e materiais tradicionais para o âmbito mais vanguardista e esnobe serve para dirimir as oposições. Como no modernismo antropofágico, o conflito identitário depende da dissolução da oposição e da alteridade colonial para ser resolvido. $\mathrm{O}$ ancestral, aquilo que marca antropofagicamente uma diferença radical, deve "ocupar" as práticas e saberes ocidentais não apenas para afirmar as raízes mas também para traduzir culturalmente as diferenças. É realmente interessante que Carol, que caminha com botas masculinas criadas para o exército, desenhe uma linha masculina andrógina. Esse desejo de explicitação da masculinidade, naturalizado para as mulheres, deve ser lido como superação da alteridade. A mulher que calça botas afirma-se como sujeito pleno; a identidade cultural que, simbolicamente, resume-se na bombacha, nas faixas bordadas ou no chapéu campeiro da roupa tradicional gaúcha, passa da posição de subalternidade feminizada para uma masculina afirmação na inovação. O sujeito antropófago decolonial 
desmonta a normatização de gênero, mas não se conforma apenas com o fato de "ingerir" a roupa. Como é característico no romance, uma linha de fuga leva de novo para um espaço liminar, onde as certezas ficam suspensas: Jean Marc, o amigo francês de Cora, que serve de modelo para seu trabalho de faculdade, propõe rematar o desenho pintando os olhos com lápis negro, uma peça da cosmética feminina plenamente incorporada na contracultura. Se a roupa arrumava o local no global, o lápis evita leituras simples de identidades apenas a partir da geopolítica e inclui a possibilidade da dissidência.

A moda é uma superfície metafórica frutífera para a negociação da identidade nacional. Se é certo que "a nação é a (com)unidade imposta, certamente não é comum a todos, sendo o espaço político e simbólico onde o patriarcado é posto em prática e resulta viável" (Sabadell-Nieto e Segarra 2014, p. 11), a roupa mostra que os "trajes" tradicionais, que proporcionam "unidade" interna e servem para distinguir uma comunidade de outra, podem fundir-se com usos e formas contemporâneas sem perder suas características. Dito de outro modo, o desenho de moda criado por Cora mostra que é possível passar de uma (com)unidade com marco identitário limitado a uma comunidade assentada nas diferenças do marco pós-identitário.

Nem as botas são apenas de homem nem a bombacha é apenas a roupa tradicional gaúcha. A moda, com sua habilidade para fundir o inconciliável, supera as diferenças normativas sexuais e nacionais.

\section{O happy end a road fiction}

É possível um happy end que não suspenda nem retenha a vida das personagens?

O romance de Bensimon é particularmente interessante em seus aspectos formais, tanto no gênero narrativo escolhido quanto em sua estrutura, particularmente pelo final bem trabalhado, que pode ser mal interpretado em uma leitura apressada.

Por ser o retrato de uma geração de mulheres a liberar-se da instituição familiar, esse romance proporciona um questionamento complexo de identidades, em especial, nas que idade e território de origem se combinam com o gênero, a identidade sexual e a classe social. A negociação identitária das mulheres nos séculos XIX e XX, isto é, da modernidade e da reivindicação feminista, representa-se com 
frequência sob os subgêneros de romance de formação, que atuam na ficção como espelhos da negociação com a normatividade social e moral estabelecida em seu contexto histórico. O bildungsroman feminino permite diversos níveis de leitura, nos quais a protagonista em primeira pessoa fala da sua experiência no mundo, de uma forma de superação de crises e do desejo de subjetividade que não lhe é permitido - e que também pode ser lido em chave pós-colonial, evidenciando as dificuldades que a antiga colônia tem para ser equiparar às antigas metrópoles. Essa primeira pessoa tem caráter modalizador: a protagonista fala com voz própria, mas também em nome do nós-outras que, a diferença do bildungsroman masculino, têm vetada a chegada a uma vida adulta plena. A instituição matrimonial, o happy end padrão da narrativa tradicional e da narrativa sentimental é, nessas ficções, visto como uma limitação para a jornada da heroína, que nunca poderá ser cidadã, que tem desejo de mundo e de superar os limites entre as esferas privada e pública. A teoria feminista liberal permite entender melhor como o fato de essa instituição social estar articulada, a partir do que Carole Pateman denomina contrato sexual, converte-a em instituição de disciplinamento, que impossibilita as mulheres de participarem da igualdade, da liberdade e da fratria sobre a qual se assenta o contrato social. Esse contrato prévio limita a participação delas na esfera pública, porque em primeiro lugar estavam sujeitas à família, e seu espaço naturalizado é o privado.

O bildungsroman feminino é o gênero que ficcionaliza a reivindicação e o feminismo no marco da modernidade, mas não descreve de maneira eficaz o desejo das mulheres na pós-modernidade. Chega mesmo a ser insuficiente para retratar as identidades de maneira complexa, em particular quando concorrem vários traços e não apenas um sujeito feminino adolescente ou jovem, branco, de classe média e com certa formação.

A road fiction aparece, no século $\mathrm{XX}$, como uma forma propriamente norte-americana: as rotas emblemáticas, como a 66 nos Estados Unidos ou a 40 na Argentina, têm seu equivalente na BR-116, que atravessa a costa de Fortaleza a Jaguarão, e que Todos nós adorávamos caubóis percorre parcialmente. Desse modo, está estreitamente ligada à criação de uma identidade individual (com a saída da casa) em relação com uma paisagem desconhecida, mas o eu também se abre a falar da comunidade. A road fiction enquanto gênero literário resolve as 
limitações ideológicas do bildungsroman feminino, com seu final sempre fracassado, porque a viagem e a vivência da liberdade permitem o processo de incorporação de sujeitos excêntricos. Refiro-me à road fiction porque o gênero se alimenta das mostras literárias e dos mais populares contributos fílmicos, portanto, é um gênero transmidiático onipresente no repertório da contemporaneidade. Esse elemento é realmente interessante no romance de Bensimon, atuando como sintoma de uma geração de mulheres que afrontam a sucessão de estranhamentos e estrangeirices identitárias (a diferença sexual, a sexualidade, a classe social, a procedência cultural, a identidade brasileira quando estão na Europa; a idade, a divergência da identidade brasileira quando falam desde Rio Grande do Sul). A viagem é uma metáfora culturalmente inteligível, e a viagem por uma paisagem que se sente própria, mas é desconhecida, situa as protagonistas no território da fronteira, sem normas e também sem fascínio, onde o eu pode construir-se a partir da experiência e do desejo. É possível perguntar, aliás, se esse não é um gênero intrinsecamente americano - embora haja romances e filmes situados em outros continentes. Há alguma coisa distintiva nesse gênero fascinado com as paisagens nas quais o peso cultural da tradição é leve e o horizonte, largo, é sempre considerado como uma sorte de espaço de fronteira, de território em movimento, ou para dizer com mais precisão, de território em devir, porque, como afirma a própria Bensimon acerca da road fiction, "não só o espaço se expande como o 'centro' do romance, passa a não ser mais tão definido" (Bensimon, 2012, s.p.).

Fazendo alusão aos referentes culturais que Carol Bensimon oferece em Todos nós adorávamos caubóis, pode-se dizer que o romance abre com o videoclipe de "Crazy", uma música de Aerosmith, no qual duas estudantes adolescentes apanham o carro e guiam rebeldes, livres, felizes, poderosas (Callner, 1994). Já sua conclusão remete ao final ambivalente do filme de Ridley Scott, Thelma $\mathcal{E}$ Louise, sujeito à dupla interpretação de se o carro suspenso no abismo é realmente um happy end metafórico ou apenas um momento fugaz de felicidade, porque ao fim a lei da gravidade leva o carro ao fracasso. Bensimon tem falado muito sobre o final como problema:

Talvez o maior desafio seja o final. Você coloca as pessoas nessa busca pela (às vezes falsa) liberdade, mas elas não podem ficar viajando para sempre, então será que elas voltam a se acomodar nas suas vidas anteriores? A maioria das narrativas de estrada (no 
cinema) disseram que não e, portanto, acabaram matando suas personagens. Foi a solução em Bonnie and Clyde, Easy Rider, Thelma $\mathcal{E}$ Louise, e muitos outros. Mas eu não quero morte agora. Nem acomodação (Bensimon, 2012, s.p.).

Todos nós adorávamos caubóis confirma, em aparência, um happy end. As duas protagonistas juntas em Paris aparecem na mesma cama. Uma leitura apressada vê nisso um final politicamente previsível: Júlia decide morar com Cora. Mas, se bem lido, na verdade, o romance acaba com um flash back: o episódio das duas garotas no leito não acontece em Paris, mas na casa da mãe de Cora, em Porto Alegre, na adolescência. A relação lésbica fica suspensa. De novo Bensimon escolhe problematizar antes que afirmar ou negar a felicidade do casal, ainda que sua relação seja legitimada e afirmada. A falta de certeza sobre qual há de ser o percurso dessa relação, o verdadeiro final de Todos nós adorávamos caubóis é o faroeste, um território no qual os corpos queerizados e decolonizados não têm limites nem identidades estáveis e, por isso, não há possibilidade de regresso. O caubói e o gaúcho, a épica do faroeste e do pampa - recolhido no tradicional "Oh de casa" dos Irmãos Bertussi citado no romance -, levam à certeza da viagem, da impossibilidade de fixar um único lugar de pertencimento, embora a experiência "nômade" seja bem diferente quando se vai a cavalo ou numa máquina, como assinala Williams em seu estudo sobre Easy Rider e, particularmente, na viagem pan-americana de Ernesto Che Guevara em Diários de uma motocicleta.

Ironicamente, a modernidade e a juventude são mostradas como deficientes em comparação com as habilidades tradicionais dos caubóis e da resistência estoica de um nativo andino. [...] Ele viaja, em relativo conforto e por escolha, a uma velocidade maior, ao passo que eles são forçados a emigrar: "A vida sem lar é o seu território" (Williams, 2007, p. 19, tradução nossa).

Assim como Thelma e Louise, as duas garotas abrem horizontes e vão vivendo. Não há felicidade final nem utopia postergada, mas também não há tristeza.

A autora citou os textos de gênero marcantes para o seu projeto ficcional, principalmente do cinema norte-americano, mas não das escritas provocadoramente pós-feministas, como o thriller Baise-moi, de Virginie Despentes, que entra no tipo de ficções de vingadoras. Se considerarmos que esse livro é condicionado pelas experiências de vida e de documentação da própria Carol Bensimon, que fez uma viagem 
exploratória pelo interior de Rio Grande do Sul e se deparou com a inconfortável tensão identitária no tempo em que viveu em Paris, nesse sentido, há uma vontade de encaixilhar o livro na experiência americana, realista, de afirmação das fugas identitárias em um território aberto e em branco no qual é possível escrever qualquer relato de liberdade que não se encaixe na conceição estática de casa, passado, identidade. A ficção de estrada fica inteligível pelo deslocamento e não por seu final. O trânsito, o processo de procura e liberação de normas de construção dos personagens com as suas tensões e contradições, a queerização frente a qualquer ordenamento e etiqueta.

\section{Referências}

BENSIMON, Carol (2012). Faíscas, novo livro de Carol Bensimon terá elementos de road novel. Entrevista a Eduardo Lemos. Saraiva Conteúdo, 9 abr. Disponível em: http://www.saraivaconteudo.com.br/Entrevistas/Post/44980. Acesso em: 10 jan. 2016.

BENSIMON, Carol (2013). Todos nós adorávamos caubóis. São Paulo: Companhia das Letras.

BENSIMON, Carol. (2014). Carol Bensimon fala sobre Todos nós adorávamos caubóis, sobre literatura, sexo e mais. Entrevista a Milton Ribeiro Sul 21, Porto Alegre, 18 jan. Disponível em: https://goo.gl/VFkwE6. Acesso em: 10 jan. 2016.

BENSIMON, Carol (2015). Todos adorábamos a los cowboys. Tradução de Malu Barnuevo. Madrid: Continta me tienes.

CALLNER, Marty (Dir.). Aerosmith: Crazy, 1994. Vídeoclipe. Disponível em: https://www.youtube.com/watch?v=Mhn4wk6iLbU. Acesso em: 10 jan. 2016.

DERRIDA, Jacques (1995). Archive fever: a freudian impression. Diacritics, Baltimore, v. 25, n. 2, p. 9-63.

GONZÁLEZ FERNÁNDEZ, Helena (2015). Presas y piratas. Memoria, nostalgia, fascinación y política de archivo. PUERTA, Aránzazu Calderón; KUMOR, Karolina; MOSZCZYNSKA-DÜRST, Katarzyna (Eds.).¿La voz dormida? Memoria y género en las literaturas hispánicas. Varsovia: Instituto de Estudios Ibéricos e Iberoamericanos, Uniwersytet Warszawski, p. 327-354.

LASTRA, Antonio (2008). Walter Mignolo y la idea de América Latina. Un intercambio de opiniones. Tabula rasa, Bogotá, n. 9, p. 285-310. Disponível em: http://www.revistatabularasa.org/numero-9/13lastra.pdf. Acesso em: 10 jan. 2016. 
MIGNOLO, Walter (2007). La idea de América Latina. La herida colonial y la opción decolonial. Barcelona: Gedisa.

MORAES, Layse (2013). Carol Bensimon. Revista TPM, São Paulo, 8 out. Disponível em: http://revistatpm.uol.com.br/so-no-site/entrevistas/carolbensimon.html. Acesso em: 10 jan. 2016.

RICH, Adrienne (1980). Compulsory heterosexuality and lesbian existence. Signs: Journas of Women in Culture and Society, Boston, v. 5, n. 4, p. 631-660.

SABADELL-NIETO, Joana; SEGARRA, Marta (2014). Impossible communities? On gender, vulnerability, and community. In: SABADELL-NIETO, Joana; SEGARRA, Marta (Ed.). Differences in common. Gender, vulnerability and community. Amsterdam; New York: Rodopi, p. 7-18.

SEGARRA, Marta (2014). Community as transit and stammering in collaborative writing. In: SABADELL-NIETO, Joana; SEGARRA, Marta (Ed.). Differences in common. Gender, vulnerability and community. Amsterdam; New York: Rodopi, p. 217-231.

WILLIAMS, Claire (2007). Los diarios de motocicleta, as Pan-American Travelogue. SHAW, Deborah (Ed.). Contemporary Latin American Cinema: Breaking into the Global Market. Lanham: Rowman \& Littlefield Publishers, p. 11-28.

Recebido em maio de 2016.

Aprovado em setembro de 2016.

\section{resumo/abstract/resumen}

\section{Romance de estrada, memória afetiva e sexualidade em Carol Bensimon}

Helena González Fernández

Em Todos nós adorávamos caubóis (2013), Carol Bensimon recorre à road fiction para construir um bildunsgroman em que as identidades sexuais ficam queerizadas. $\mathrm{O}$ fato de transitar por territórios geográficos, corporais e afetivos sentidos como próprios e ao mesmo tempo desconhecidos evidencia as múltiplas tensões e contradições que impedem sucumbir à promessa da felicidade e, pelo contrário, opõe-se a qualquer redução identitária. O remate do relato, um happy end de dupla leitura, reforça um projeto de escrita renovador.

Palavras-chave: road fiction, queer, bildungsroman, Carol Bensimon. 


\section{Road fiction, affective memory and sexuality in Carol Bensimon}

Helena González Fernández

In Todos nós adorávamos caubóis (2013) Carol Bensimon uses the road story to construct a bildungsroman that queers sexual identities. The journey through geographical, bodily and affective territories that are perceived as both known and unfamiliar, showcases the many tensions and contradictions that keeps someone from succumbing to the promise of happiness. Rather, this movement is antagonistic to any limits imposed upon the construction of identity. The happy ending of the story, which lends itself to a two-fold interpretation, reinforces an innovative writing project.

Keywords: road fiction, queer, bildungsroman, Carol Bensimon.

\section{Novela de carretera, memoria afectiva y sexualidad en Carol Bensimon}

Helena González Fernández

En Todos nós adorávamos caubóis (2013) Carol Bensimon recurre a la road fiction para construir una novela de formación en la que las identidades sexuales son queerizadas. El hecho de transitar por territorios geográficos, corporales y afectivos que se sienten como propios y al mismo tiempo desconocidos evidencia las muchas tensiones y contradicciones que impiden sucumbir a la promesa de la felicidad y, por el contrario, se oponen a cualquier reducción identitaria. El final del relato, un happy end de doble lectura, refuerza un proyecto de escritura renovador.

Palabras clave: road fiction, queer, bildungsroman, Carol Bensimon. 